\title{
BIOMIMETIC DEPOSITION OF APATITE ON SURFACE CHEMICALLY MODIFIED POROUS NITI SHAPEMEMORY ALLOY
}

\author{
S.L. WU, X.M. LIU, C.Y. CHUNG ${ }^{*}$, PAUL K. CHU \\ Department of Physics \& Materials Science, City University of Hong Kong, Tat Chee Avenue, \\ Kowloon, Hong Kong \\ appchung@cityu.edu.hk \\ Y.L. CHAN and K.W.K. YEUNG \\ Division of Spine Surgery, Department of Orthopaedics and Traumatology, The University of Hong \\ Kong, Pokfulam, Hong Kong \\ C.L. CHU \\ School of Materials Science and Engineering, Southeast University, Nanjing 210018, \\ China
}

\begin{abstract}
Porous NiTi shape memory alloy (SMA) with $48 \%$ porosity and an average pore size of $50-800 \mu \mathrm{m}$ was synthesized by capsule-free hot isostatic pressing (CF-HIP). To enhance the surface bioactivity, the porous NiTi SMA was subjected to $\mathrm{H}_{2} \mathrm{O}_{2}$ and subsequent $\mathrm{NaOH}$ treatment. Scanning electron microscopy (SEM), X-ray diffraction (XRD), and X-ray photoelectron spectroscopy (XPS) analyses revealed that a porous sodium titanate $\left(\mathrm{Na}_{2} \mathrm{TiO}_{3}\right)$ film had formed on the surface of the porous NiTi SMA. An apatite layer was deposited on this film after immersion in simulated body fluid (SBF) at $37^{\circ} \mathrm{C}$, while no apatite could be found on the surface of the untreated porous NiTi SMA. The formation of the apatite layer infers that the bioactivity of the porous NiTi SMA may be enhanced by surface chemical treatment, which is favorable for its application as bone implants.
\end{abstract}

Keywords: Porous NiTi; Shape memory alloy; Surface modification; Apatite; Bioactivity; Biomimetic.

\section{Introduction}

Porous NiTi shape memory alloys (SMAs) from powder metallurgical (PM) methods have attracted considerable attentions in orthopedic fields as one of most promising biomaterials for hard tissue repair and reconstruction applications [1-4], which is due to its excellent superelasticity (SE), good mechanical properties and interconnected open porous structure. 1, 2, 5-9. However, the high nickel content of NiTi alloys is of great concern affecting its biocompatibility because the released nickel ions was reported one of the causes for some allergic contact dermatitis and asthma. ${ }^{10-12}$ The large exposed surface area of the porous structure makes porous alloy more susceptible to nickel-leaching than dense NiTi SMAs, ${ }^{13}$ and the complex surface morphology makes it more difficult to modify the entire exposed surface of the porous NiTi SMAs by common line-of-sight PVD techniques. The development of non-line-ofsight methods, ${ }^{5,14-17}$ such as chemical treatment is needed.

Chemical treatments have been reported to be effective in modifying the surface of $\mathrm{Ti}$ and
Ti-based alloys to favor the formation of bioactive apatite on the surface in simulated body fluids (SBF) and prevent nickel ions from leaching-out from the dense NiTi SMAs. ${ }^{18-30}$ It is believed that this method is suitable for modifying the complex surface of porous NiTi due to its non-line-of-sight nature better than plasma immersion ion implantation (PIII) and air oxidation. 5, 16, 17 In chemical treatment, different chemical solutions such as hydrogen peroxide solution $\left(\mathrm{H}_{2} \mathrm{O}_{2}\right), \mathrm{H}_{2} \mathrm{SO}_{4}$ and $\mathrm{NHO}_{3}$ were often used to pre-treat titanium metal to form a layer of titania film followed by alkaline treatment. ${ }^{31-35}$ However, these reports focused on the enhancement of surface bioactivity of dense materials, and few studies were carried out on porous NiTi SMAs. The recent investigation of Jiang and Rong revealed that $\mathrm{HNO}_{3}$ solution and subsequent $\mathrm{NaOH}$ treatment can enhance the formation of hydroxyapatite (HA) on the surface of porous NiTi immersed in SBF. ${ }^{13}$ It also depressed nickel-leaching, and they ascribed the superior behavior to the formation of $\mathrm{TiO}_{2}$ and $\mathrm{NaTiO}_{3}$. However, there is no systematical analysis of the surface structure of the exposed 
pores prior the formation of HA.

In this work, porous NiTi SMAs fabricated by capsule-free hot isostatic pressing (CF-HIP) were chemically pre-treated by $\mathrm{H}_{2} \mathrm{O}_{2}$ and subsequent $\mathrm{NaOH}$ treatment. The surface chemically modified NiTi SMAs were subsequently immersed in SBF for various periods of time to investigate their biomimetic apatite-forming ability. Scanning electron microscopy (SEM), small area X-ray photoelectron spectroscopy (XPS) were used to characterize the layer produced by chemical modification and the apatite formed in porous NiTi SMAs.

\section{Experimental Details}

Porous NiTi SMAs were fabricated using thoroughly mixed equiatomic $\mathrm{Ni}$ and Ti powders by capsule-free hot isostatic pressing. The mixed powders were compressed into a rod shape green compacts by a uniaxial hydraulic press. The green compact was hot isostatic pressing (HIP) chamber which was vacuumed and backfilled with pure argon. The argon pressure and temperature were then raised simultaneously to $150 \mathrm{MPa}$ and $1050{ }^{\circ} \mathrm{C}$ respectively. The high pressure and temperature were kept for 3 hours allowing sufficient solid state diffusion of the nickel and titanium. Details of the CF-HIP process can be found in our previous publications. $^{36,37}$ The porosity of the sample was about $48 \%$, which was calculated using by the equation:

$$
p=\left(1-\rho / \rho_{0}\right) \times 100 \%
$$

Where $\rho$ is the density of the porous NiTi SMAs (mass/the theoretical volume), $\rho_{0}$ is $6.45 \mathrm{~g} / \mathrm{cm}^{3}$ (the theoretical density) of $\mathrm{NiTi}$ SMAs. The open porosity was approximately $70 \%$, which is determined according to the ASTM B328-96 protocol. $^{38}$ The pore size of porous NiTi SMAs was found in the range of $100-600 \mu \mathrm{m}$. The samples used for chemical modification were cut into disks $6 \mathrm{~mm}$ in diameter and $2 \mathrm{~mm}$ thick from the porous NiTi SMAs. They were mechanically polished progressively from 240 to 800 grits sandpapers, ultrasonically cleaned with acetone and rinsed with de-ionized water before leaving to dry overnight in air at room temperature.

Before treatment, the samples were divided into two groups. The first group was used as control without treatment. The second group was oxidized for 4 hours in an $80^{\circ} \mathrm{C}$ aqueous solution containing $30 \% \mathrm{H}_{2} \mathrm{O}_{2}$, then ultrasonically rinsed with de-ionized water for $20 \mathrm{~min}$. Subsequently, these samples were treated in $10 \mathrm{M} \mathrm{NaOH}$ aqueous solution at $60^{\circ} \mathrm{C}$ for 24 hours, and finally ultrasonically cleaned and rinsed with de-ionized water for 20min. For the above treated and untreated samples, each sample was incubated in $25 \mathrm{ml}$ of SBF with a $\mathrm{pH}$ value of 7.42 at $37 \pm 0.5^{\circ} \mathrm{C}$. The SBF composed of 7.996 $\mathrm{g} / 1$ of $\mathrm{NaCl}, 0.35 \mathrm{~g} / 1$ of $\mathrm{NaHCO}_{3} .0 .224 \mathrm{~g} / \mathrm{l}$ of $\mathrm{KCl}, 0.228 \mathrm{~g} / 1$ of $\mathrm{K}_{2} \mathrm{HPO}_{4} \cdot 3 \mathrm{H}_{2} \mathrm{O}, 0.305 \mathrm{~g} / \mathrm{l}$ of $\mathrm{MgCl}_{2} \cdot 6 \mathrm{H}_{2} \mathrm{O}, 0.278 \mathrm{~g} / \mathrm{l}$ of $\mathrm{CaCl}_{2}, 0.071 \mathrm{~g} / \mathrm{l}$ of $\mathrm{Na}_{2} \mathrm{SO}_{4}$, as well as $6.057 \mathrm{~g} / 1\left(\mathrm{CH}_{2} \mathrm{OH}\right)_{3} \mathrm{CNH}_{2}$, with ionic concentrations similar to human body blood plasma. ${ }^{39}$ After the samples were immersed for various periods of time, i.e. 5, 10 and 15 days, they were removed from the solution, gently rinsed with de-ionized water, and dried at room temperature. The nickel concentration in the corresponding SBF was measured using inductively-coupled plasma mass spectrometry (ICPMS) [Perkin Elmer, PE SCIEX ELAN6100, USA]. During the immersion tests, the SBF solution was not replenished.

The surface morphologies of the samples were examined using scanning electron microscope (SEM JSM820) equipped with an energy-dispersive spectroscopy (EDS). EDS was performed to determine the composition of the modified surface. A field emission scanning electron microscope (FESEM, JEOL JSM-6335F) was used examine the morphology of the bioactive layer. Thin film X-ray diffraction (TF-XRD) measurement was conducted using a Philips X'pert X-ray diffractomer $(\mathrm{CuK} \alpha$ radiation, $40 \mathrm{kV}, 30 \mathrm{~mA}$, grazing incidence at $\left.5^{\circ}\right)$. The data were collected in the $2 \theta$ range of $20^{\circ}-50^{\circ}$ with a step increment of $0.01^{\circ}$. The chemical composition depth profile were determined by X-ray photoelectron spectroscopy (XPS) [Physical electronics PHI 5802, Minnesota, USA] using an aluminum X-ray source with a power of $350 \mathrm{~W}$. The take-off angle was $45^{\circ}$ and the base vacuum was $2 \times 10^{-8}$ Pa. Survey scans were first conducted to measure the elemental species on the surfaces over a binding energy range of $0-1400 \mathrm{eV}$ in 0.8 eV steps using a pass energy of $187.85 \mathrm{eV}$. In order to determine the composition of the exposed surface, high resolution small area (120 $\mu \mathrm{m})$ XPS analysis was performed on the wall of one of the internal pore using a pass energy of 
$11.75 \mathrm{eV}$ and $0.1 \mathrm{eV}$ step. A GaussianLorentzian peak fitting model was used to deconvolute the special narrow scan spectra such as Na1s, O1s, Ti2p and Ni 2p.

\section{Results and discussion}

Fig. 1 (a) shows the typical surface morphology of porous NiTi SMA fabricated by CF-HIP. The size of most pores was in the range of $50-800 \mu \mathrm{m}$ and interconnected. This interconnected porous structure with big pore size allows the tissue in-growth and favors the fixation of bone implants. It can be found from Fig. 1(b) that, after oxidization in $\mathrm{H}_{2} \mathrm{O}_{2}$ solution, a rough layer of oxides with some micro-crack formed on the surface, which was confirmed by the XPS results. (Details will be discussed in the part of XPS Analysis.)After treatment in $\mathrm{NaOH}$ solution with
$\mathrm{H}_{2} \mathrm{O}_{2}$ preoxidation, a layer of spiculate structure forms on the surface of porous NiTi SMA [shown in Fig. 1(c)]. High magnification FESEM image reveals that this layer is a porous film with homogeneous distributed nano pores [shown in Fig. 1 (d)]. After 5 days immersion in SBF at $37{ }^{\circ} \mathrm{C}$, some precipitates were found on the surface with discontinuous distribution [Fig. 1 (e)]. The amount and size of these precipitates increased as the immersion time increased. After immersion in SBF at $37{ }^{\circ} \mathrm{C}$ for 15 days, the surface was almost completely covered by a layer of such precipitates [Fig. 1 (f)]. Higher magnification image revealed that there were small pores on the precipitated particles [Fig. 1 (g)].
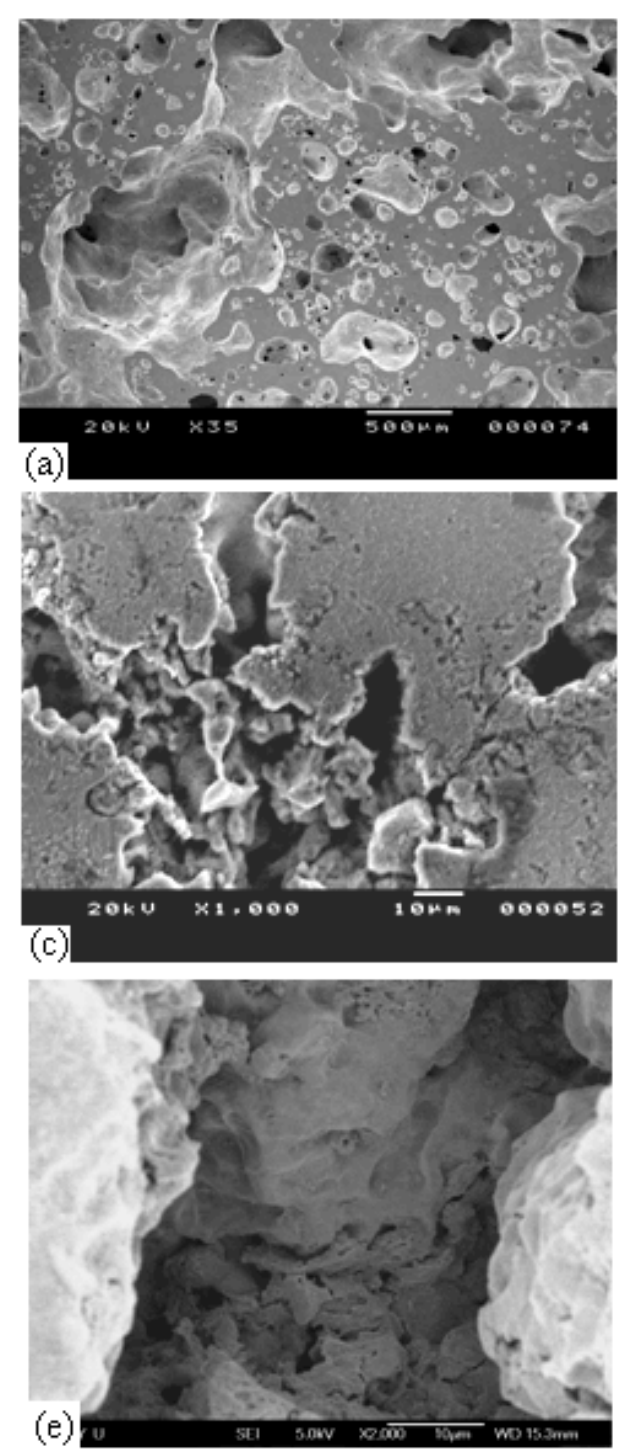
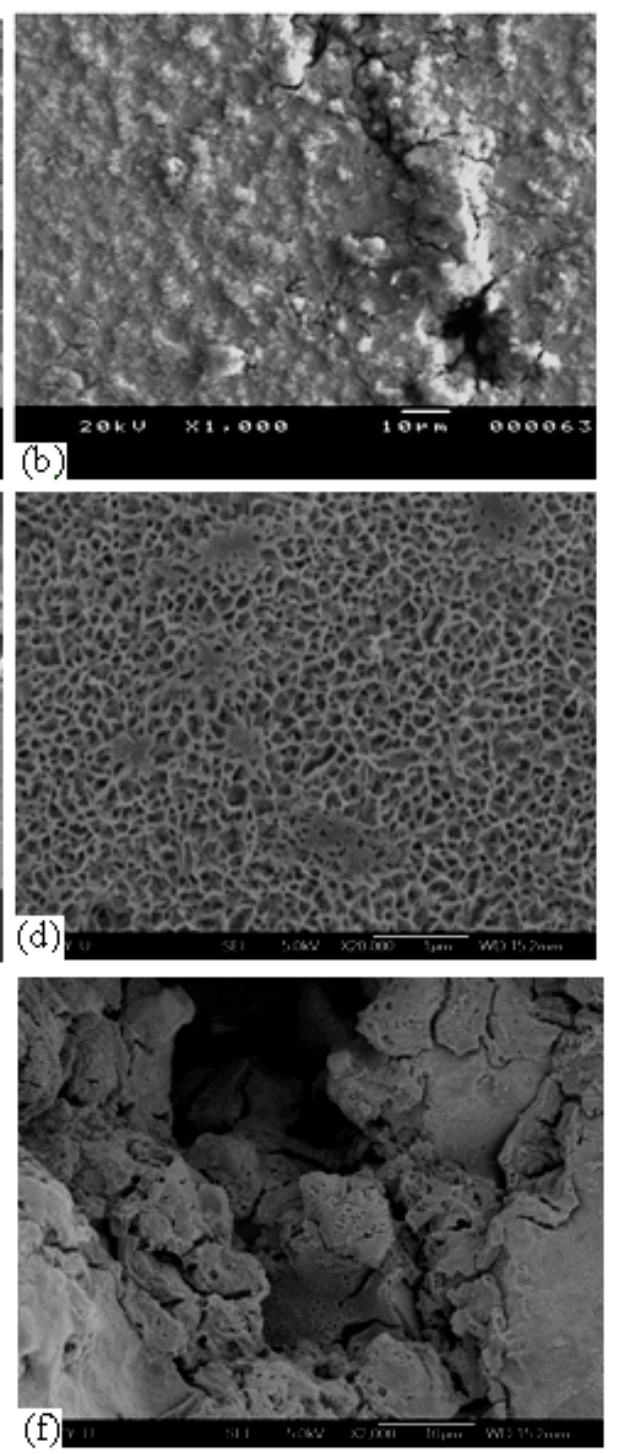


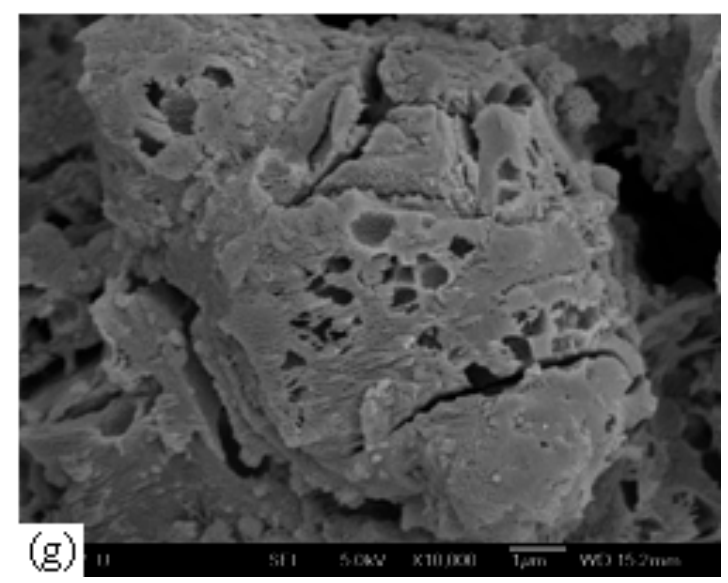

Fig. 1. Morphology of porous NiTi: (a) typical surface morphology of the untreated porous NiTi fabricated by capsule-free hot isostatic pressing; (b) after $\mathrm{H}_{2} \mathrm{O}_{2}$ aqueous treatment; (c) after $\mathrm{H}_{2} \mathrm{O}_{2}$ aqueous pretreatment and subsequent $\mathrm{NaOH}$ aqueous treatment; (d) high magnification image of (c); sample shown in (c) after immersion in SBF for (e) 5 days and (f) 15 days; (g) high magnification image of (f);
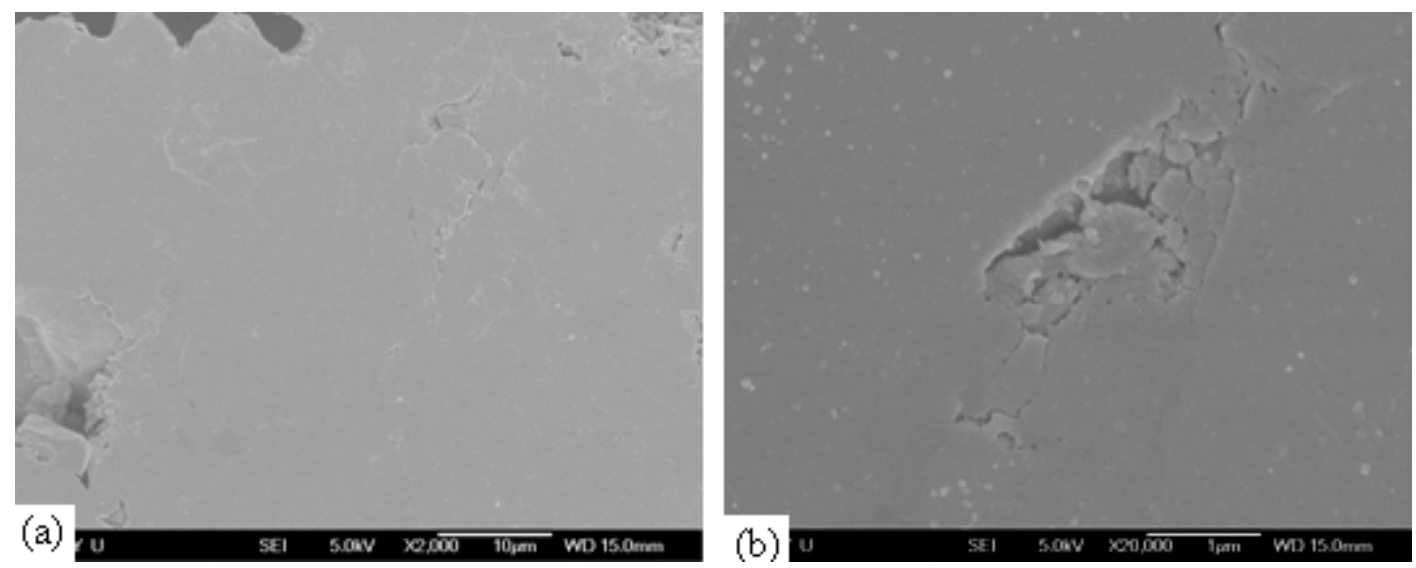

Fig. 2. Micrographs of the untreated porous NiTi SMA immersed in SBF (a) for 15 days; (b) high magnification image of (a);

In comparison, Figs.2 (a) and (b) shows the surface micrograph and the corresponding high magnification image of the untreated porous NiTi SMA immersed in SBF at $37{ }^{\circ} \mathrm{C}$ for 15 days. There was no precipitate found on the surface of the untreated porous sample, which reveals that $\mathrm{Na}_{2} \mathrm{TiO}_{3}$ (confirmed by EDS, XRD and XPS in the next parts) formed on porous NiTi alloy by chemically modification is bioactive and favor the formation of the bone-like apatite. The EDS results shown in Fig. 3 indicates that the precipitates contain calcium and phosphorous. The peaks of $\mathrm{Na}$ and $\mathrm{O}$ can also be detected. The signal of $\mathrm{Ti}$ and $\mathrm{Ni}$ should come from the NiTi alloy substrate. Fig. 4 shows the TF-XRD pattern of surface chemically modified porous NiTi immersed in SBF for 15 days at $37{ }^{\circ} \mathrm{C}$. It was found that the precipitated layer mainly composed of apatite. Minor $\mathrm{TiO}_{2}$ and $\mathrm{Na}_{2} \mathrm{TiO}_{3}$ exist on the surface layer, which could be the products of chemical reaction during the chemical modification process [13].

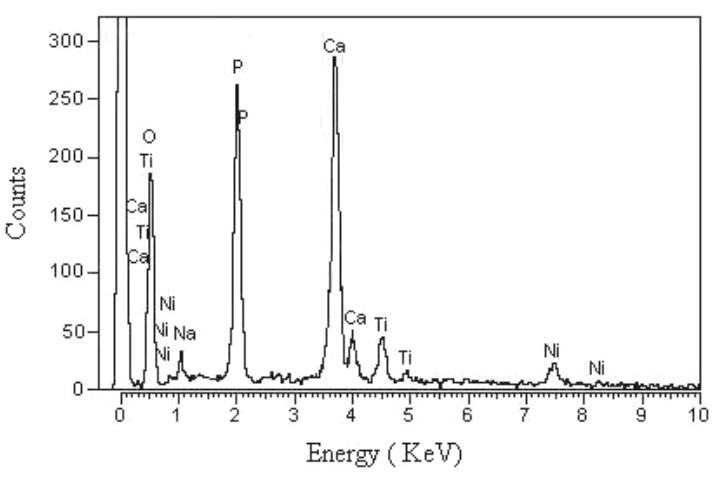

Fig. 3. SEM-EDS profile of the surface chemically modified porous NiTi alloy after immersed in SBF for 15 days; 


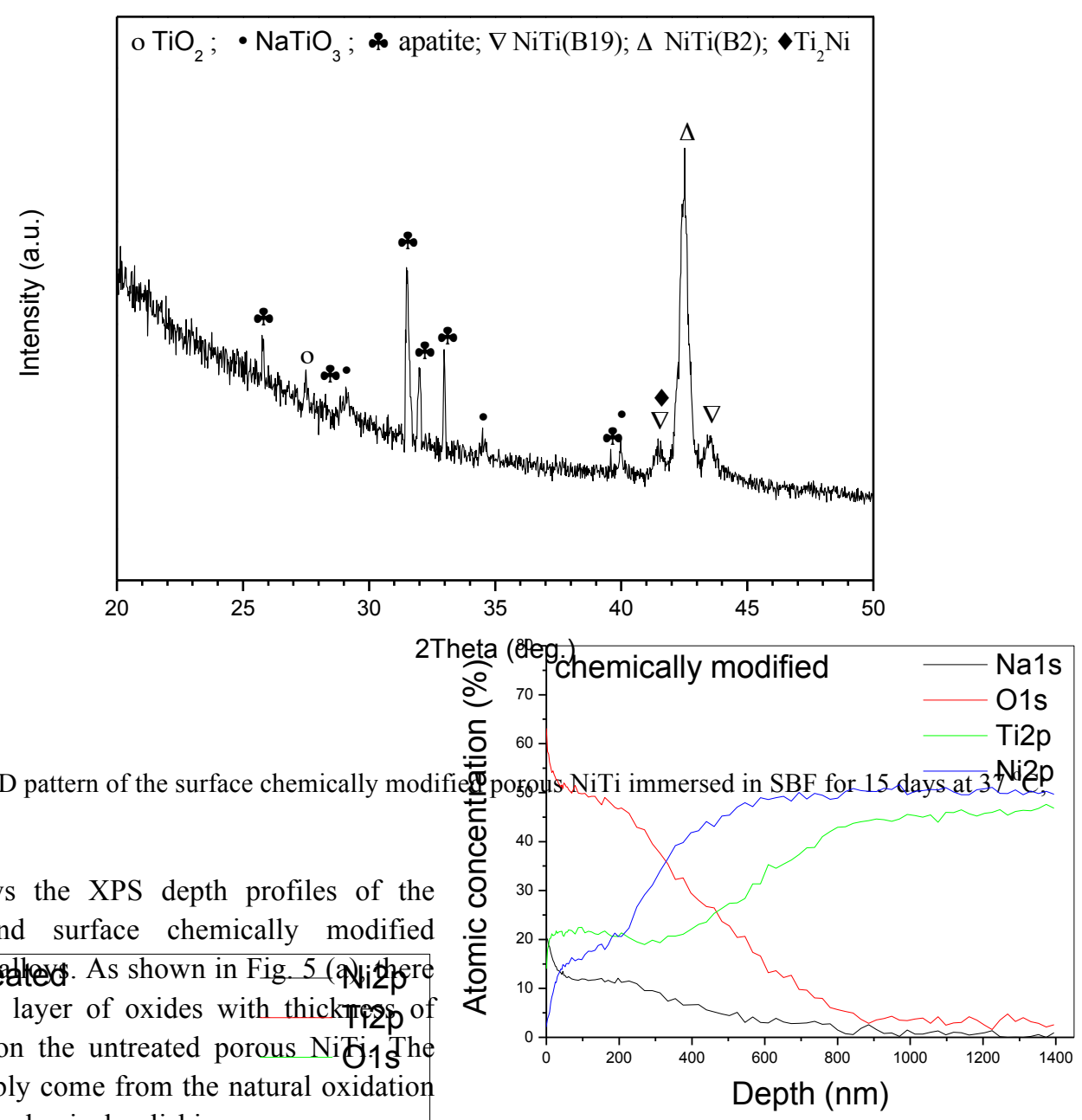

Fig. 5 shows the XPS depth profiles of the untreated and surface chemically modified

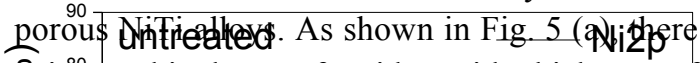
\&xists a thin layer of oxides with thick mp2 $\mathrm{p}^{\circ}$ Several $\mathrm{nm}$ on the untreated porous Nifi $1 \mathrm{The}$
Depth $(\mathrm{nm})$

Fig. 4. TF-XRD pattern of the surface chemically modifies posouis NiTi immersed in SBF for 15 days at $3 \mathrm{Ni} 2 \mathrm{p}$

(b)

Fig. 5. XPS depth profile of the porous NiTi: (a) untreated sample; (b) surface chemically modified sample;

The high resolution XPS narrow spectra shown in Fig. 6 (a) reveals that this layer mainly composed of $\mathrm{TiO}_{2}$, minor $\mathrm{TiO}$ and $\mathrm{NiTi}$ (according to the fitting curve of Ti2p spectra, not shown here) [5]. In comparison, for surface chemically modified porous NiTi, the thickness of the surface layer was about $800 \mathrm{~nm}$ thick, which exhibits a graded structure [shown in Fig. 5 (b)]. 
Fig. 6 (b) shows the high resolution XPS narrow spectra of Ti2p of the surface chemically modified porous NiTi alloy. It is obvious that from the surface to the substrate, Ti2p3/2 exhibits three different binding energies of 458.3 $\mathrm{eV}, 459.1 \mathrm{eV}$ and $454.5 \mathrm{eV}$, corresponding to the surface layer, the middle layer and the substrate, respectively. According to the reported binding energies of Ti2p3/2 in different compounds [40], Ti2 $p$ signal from the surface layer can be attributed to $\mathrm{TiO}_{3}{ }^{2-}$. In the middle layer, Ti2 $p$ should be de fip to $\mathrm{TiO}_{2}$ and $\mathrm{TiO}_{3}{ }^{2-}$ (aceording to the fitting curve of Ti2p spectra, not shown here). As the depthincreases, the amount of $\mathrm{TiO}_{2}$ and

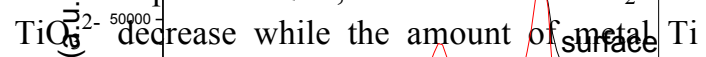

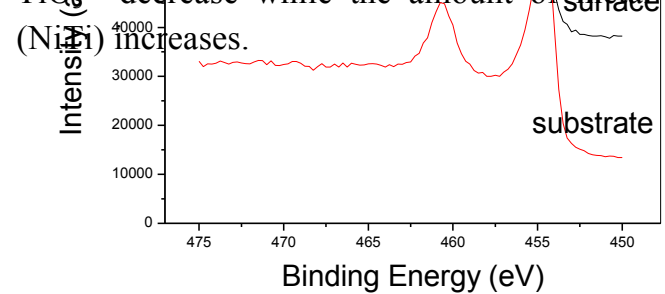

(a)

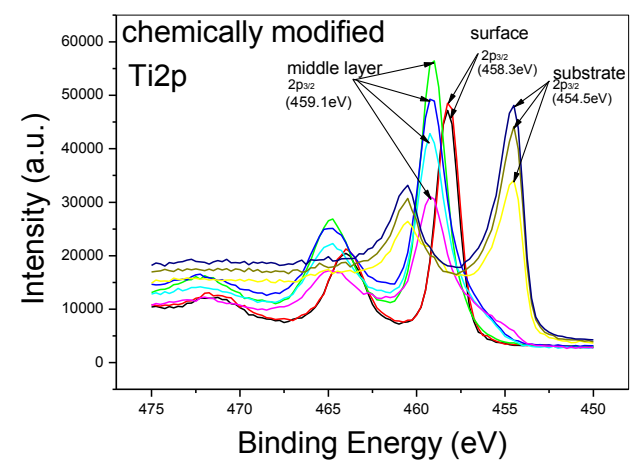

(b)

Fig. 6. High resolution XPS narrow spectra of Ti2p; (a) untreated sample; (b) surface chemically modified sample;

Combined with the depth profile curves shown in Fig. 5 (b), it was evident that the surface layer of surface chemically modified porous $\mathrm{NiTi}$ alloy was dominantly composed of $\mathrm{Na}_{2} \mathrm{TiO}_{3}$, while the middle layer composed of $\mathrm{TiO}_{2}$, $\mathrm{Na}_{2} \mathrm{TiO}_{3}$ and trace amount of NiTi. The amount of $\mathrm{TiO}_{2}$ and $\mathrm{Na}_{2} \mathrm{TiO}_{3}$ gradually decrease when it was closer to the substrate. Binding energy signals of NiTi dominate when the depth was more than $800 \mathrm{~nm}$.

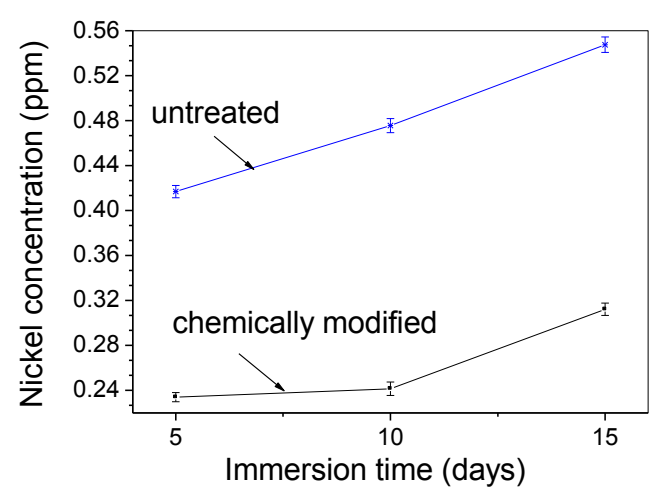

Fig. 7. Nickel release concentration of porous NiTi samples at different immersion duration in SBF.

The amount of nickel released from the untreated and surface chemically modified porous samples to the SBF for different time duration is shown in Fig. 7. For both of the untreated and surface chemically modified porous samples, the amount of nickel released increased when the immersion time increased. The nickel released from the surface chemically modified sample decreased significantly. This can be the effect of the $800 \mathrm{~nm}$ thick graded layer composed of $\mathrm{Na}_{2} \mathrm{TiO}_{3}$ and $\mathrm{TiO}_{2}$ formed on the surface of porous NiTi alloy [shown in Fig 5(b)], which prevents the nickel leaching-out from the substrate. Furthermore, this graded layer can facilitate the nucleation and growth of apatite in SBF. The enhanced deposition of apatite also lead to more effective blocking of the nickel released from the NiTi substrate. For the untreated porous $\mathrm{NiTi}$, there exist only several $\mathrm{nm}$ nature oxides on the surface.

\section{Conclusions}

A graded bioactive layer mainly composed of $\mathrm{Na}_{2} \mathrm{TiO}_{3}$ and $\mathrm{TiO}_{2}$ can be prepared on the surface of porous NiTi SMA by $\mathrm{H}_{2} \mathrm{O}_{2}$ and subsequent $\mathrm{NaOH}$ treatment, which is favorable for the biomimetic deposition of bone-like apatite on the surface of porous NiTi alloy in $\mathrm{SBF}$ at $37{ }^{\circ} \mathrm{C}$ in comparison with the untreated porous sample. Furthermore, as a non-line-ofsight modification technique, chemical surface modification can also effectively hinder the nickel out leakage from porous NiTi alloys with 
complex surface morphology and large exposed area.

\section{Acknowledgements}

This work was jointly supported by Hong Kong Research Grants Council (RGG) Central Allocation Group Research Grant No. CityU 1/04C, City University of Hong Kong Applied Research Grant No. 9667002 and the SRG grant from the Research Committee of the CityU of HK (Project \#: 7001999).

\section{References}

1. Itin VI, Gyunter VE, Shabalovskaya SA, Sachdeva RLC. Mechanical properties and shape memory of porous nitinol. Mater Charact 1994; 32: 179.

2. Li BY, Rong LJ, Li YY, Gjunter VE. Synthesis of porous Ni-Ti shape-memory alloys by self-propagating high-temperature synthesis reaction mechanism and anisotropy in pore structure. Acta Mater 2000; 48: 3895

3. Silbersteinm BM, Gjunter VE. Shape-Memory Implants in Spinal Surgery, Springer, Berlin, 2000, p. 147.

4. Simske SJ, Sachdeva R. Cranial bone apposition and ingrowth in a porous nickel-titanium implant. J Biomed Mater Res 1995; 29: 527.

5. Wu SL, Chu PK, Liu XM, Chung CY, Ho JPY, Chu CL, Tjong SC, Yeung KWK, Lu WW, Cheung KMC, Luk KDK. Surface characteristics, mechanical properties, and cytocompatibility of oxygen plasma-implanted porous nickel titanium shape memory alloy. J Biomed Mater Res A 2006; 79: 139

6. Greiner C, Oppenheimer SM, Dunand DC. High strength, low stiffness, porous NiTi with superelastic properties. Acta Biomaterialia 2005; 1: 705.

7. Zhao Y, Taya M, Kang YS, Kawasaki A. Compression behavior of porous NiTi shape memory alloy. Acta Mater 2005; 53: 337.

8. Prymak O, Bogdanski D, Koller M, Esenwein SA, Muhr G, Beckmann F, Donath T, Assad M, Epple M. Morphological characterization and in vitro biocompatibility of a porous nickel-titanium alloy. Biomaterials 2005; 26: 5801

9. Chu CL, Chung CY, Lin PH, Wang SD. Fabrication and properties of porous NiTi shape memory alloys for heavy load-bearing medical applications. J Mater.
Process Technol 2005; 169: 103

10. Peltonen L. Nickel sensitivity in the general population. Contact Dermatitis 1979; 5: 27.

11. Barrett RD, Bishara SE, Quinn JK. Biodegradation of orthodontic appliances. 1. biodegradation of nickel and chromium in vitro. Am. J. Orthod. Dentofac. Orthoped. 1993; 103: 8.

12. Rondelli G, Vicentini B. Bone modeling and cell-material interface responses induced by nickel-titan ium shape memory alloy after periosteal implantation. Biomaterials 1999; 20: 1309.

13. Jiang HC, Rong LJ. Effect of hydroxyapatite coating on nickel release of the porous NiTi shape memory alloy fabricated by SHS method, Surface \& Coatings Technology 2006; 201: 1017.

14. Cui ZD, Man HC, Yang XJ. Characterization of the laser gas nitrided surface of NiTi shape memory alloy. Appl Surf Sci 2003; 208: 388.

15. Lotkov AI, Meisner LL, Grishkov VN. Titanium nickelide-based alloys: Surface modification with ion beams, plasma flows, and chemical treatment. Phys Met Metallogr 2005; 99: 508.

16. Wu SL, Liu XM, Chan YL, Ho J PY, Chung CY, Chu PK, Chu CL, Yeung KW $\mathrm{K}$, Lu WW, Cheung KMC, Luk KDK, "Nickel Release Behavior, Cyto-Compatibility, and Superelasticity of Oxidized Porous Single-Phase NiTi”, Journal of Biomedical Materials Research A (in press) 2007. DOI: 10.1002/jbm.a.31115

17. Gu YW, Tay BY, Lim CS, Yong MS. Biomimetic deposition of apatite coating on surface-modified NiTi alloy, Biomaterials 2005; 26: 6916.

18. Ken Nishio, Masashi Neo, Haruhiko Akiyama, Shigeru Nishiguchi, Hyun-Min Kim, Tadashi Kokubo, Takashi Nakamura. The effect of alkali- and heat-treated titanium and apatite-formed titanium on osteoblastic differentiation of bone marrow cells, J Biomed Mater Res 2000; 52: 652.

19. Yong Han, Tao Fu, Jian Lu, Kewei Xu. Characterization and stability of hydroxyapatite coatings prepared by an electrodeposition and alkaline-treatment process, Journal of Biomedical Materials Research 2001; 54: 96.

20. Wang XX, Hayakawa S, Tsuru K, Osaka A. A comparative study of in vitro apatite deposition on heat-, $\mathrm{H}_{2} \mathrm{O}_{2^{-}}$, and $\mathrm{NaOH}$-treated titanium surfaces, J Biomed Mater Res 2001; 54: 172. 
21. Wang XX, Hayakawa S, Tsuru K, Osaka A. Improvement of the bioactivity of $\mathrm{H}_{2} \mathrm{O}_{2} / \mathrm{TaCl}_{5}$-treated titanium after a subsequent heat treatment. J Biomed Mater Res 2000;52: 171.

22. Kokubo T, Miyaji F, Kim HM, Nakamura $\mathrm{T}$. Spontaneous formation of bone-like apatite layer on chemically treated titanium metals. J Am Ceram Soc 1996; 79: 1127.

23. Wen HB, Liu Q, De Wijn JR, De Groot K. Preparation of bio-active microporous titanium surface by a new two-step chemical treatment. J Mater Sci: Mater Med 1998; 9: 121.

24. Ohtsuki C, Iida H, Hayakawa S, Osaka A. Bioactivity of titanium treated with hydrogen peroxide solution containing metal chlorides. J Biomed Mater Res 1997; 35: 39 .

25. Kim HM, Miyaji F, Kokubo T, Nakamura T. Preparation of bioactive Ti and its alloys via simple chemical surface treatment. J Biomed Mater Res 1996; 32: 409.

26. Wen HB, De Wijn JR, Cui FZ, De Groot K. Preparation of bioactive Ti6A14V surfaces by a simple method. Biomaterials 1998; 19: 215.

27. Chu CL, Chung CY, Zhou J, Pu YP, Lin P H. Fabrication and characteristics of bioactive sodium titanate/titania graded film on $\mathrm{NiTi}$ shape memory alloy. J Biomed Mater Res 2005; 75A: 595.

28. Miyazaki T, Kim HM, Miyaji F, Kokubo T, Kato H, Nakamura T. Bioactive tantalum metal prepared by $\mathrm{NaOH}$ treatment. J Biomed Mater Res 2000; 50: 35.

29. Chen MF, Yang XJ, Liu Y, Zhu SL, Cui ZD, Man HC, Study on the formation of an apatite layer on NiTi shape memory alloy using a chemical treatment method, Surf. Coat. Technol. 2003;173: 229

30. Shi P, Geng F, Cheng FT. Preparation of titania-hydroxyapatite coating on NiTi via a low-temperature route, Materials Letters 2006; 60: 1996.

31. Wen HB, de Wijin JR, Cui FZ, de Groot K. Preparation of calcium phosphate coatings on titanium implant materials by simple chemistry. J Biomed Mater Res 1998; 41: 227.

32. de Andrade MC, Filgueiras MRT,
Ogasawara T. Nucleation and growth of hydroxyapatite on titanium pretreated in $\mathrm{NaOH}$ solution. Experiments and thermodynamic explanation. J Biomed Mater Res 1999;46:441.

33. Xiao F, Tsuru K, Hayakawa S, Osaka A. In vitro apatite deposition on titania film derived from chemical treatment of $\mathrm{Ti}$ substrates with an oxysulfate solution containing hydrogen peroxide at low temperature. Thin Solid Films 2003; 441: 271

34. Jonasova L, Muller FA, Helebrant A, Strnad J, Greil P. Biomimetic apatite formation on chemically treated titanium. Biomaterials 2004; 25: 1187.

35. Kim HM, Miyaji F, Kokubo T, Nishiguchi S, Nakamura T. Graded surface structure of bioactive titanium prepared by chemical treatment. J Biomed Mater Res 1999; 45: 100.

36. Wu SL, Liu XM, Chu PK, Chung CY, Chu CL, Yeung KWK. Phase transformation behaviour of porous NiTi alloys fabricated by capsule-free hot isostatic pressing, Journal of Alloys and Compounds, in press, DOI 10.1016/j.jallcom.2006.01.144.

37. Wu SL, Chung CY, Liu XM, Chu PK, Ho JPY, Chu CL, Chan YL, Yeung KWK, Lu WW, Cheung KMC, and Luk KDK. Pore formation mechanism and characterization of porous NiTi shape memory alloys synthesized by capsule-free hot isostatic pressing, Acta Mater (2007), doi:10.1016/j.actamat.2007.01.045

38. ASTM Standard B328-96 (Reapproved 2003). American Society for Testing and Materials, Philadelphia, PA, 2003

39. Kokubo T, Kushitani H, Sakka S, Kitsugi T, Yamamuro T. Solutions able to reproduce in-vivo surface-structure changes in bioactive glass-ceramic A-W. J Biomed Mater Res 1990; 24: 721.

40. Moulder JF, Stickle WF, Sobol PE, Bomben KD, Chastain J. Handbook of X-Ray Photoelectron Spectroscopy: A Reference Book of Standard Spectra for Identification and Interpretation of XPS Data. Minnesota: Perkin-Elmer, Physical Electronics Division; 1992. 